\title{
Chapter 5 \\ Producing and Communicating Flood \\ Risk: A Knowledge System Analysis of FEMA Flood Maps in New York City
}

\author{
Robert Hobbins, Tischa A. Muñoz-Erickson, and Clark Miller
}

\begin{abstract}
The burgeoning development of coastal cities coupled with increasing exposure to sea level rise and extreme weather events has exacerbated the vulnerability of coastal communities and infrastructure to floods. In order to make good flood risk reduction and resilience decisions, cities are interested in gaining better insights into what are perceived to be the "real" risks of floods. However, what counts as a good estimate of such risks is constructed through the design of a knowledge system that ratifies certain ideas and methods over others. We refer to knowledge systems as the organizational practices and routines that produce, validate and review, communicate, and use knowledge relevant to policy and decision-making. In this chapter, we conduct a knowledge system analysis of FEMA's Flood Insurance Rate Maps in New York City. In 2012, Superstorm Sandy exposed in the national spotlight the shortcomings of how we calculate, map, and use knowledge about flood risk. Through this case study, we hope to demonstrate the value of knowledge systems analysis as a method to stress-test and identify the weaknesses of a knowledge system that warrant attention, as well as to inform potential methods ofupgrading or redesigning that system in support of building resilient cities.
\end{abstract}

Keywords Knowledge systems analysis $\cdot$ National flood insurance program $\cdot$ Risk communication $\cdot$ Climate resilience

\footnotetext{
R. Hobbins $(\bowtie)$

School of Sustainability, Arizona State University, Tempe, AZ, USA

e-mail: rhobbins@asu.edu
}

\section{T. A. Muñoz-Erickson}

USDA Forest Service, International Institute of Tropical Forestry, Río Piedras, PR, USA

C. Miller

School for the Future of Innovation in Society, Arizona State University, Tempe, AZ, USA

(C) This is a U.S. government work and not under copyright protection in the U.S.; 


\subsection{Introduction}

The burgeoning development of coastal cities coupled with increasing exposure to sea level rise and extreme weather events has exacerbated the vulnerability of coastal communities and infrastructure to floods. One trillion dollars in United States' coastal assets are currently vulnerable to coastal floods, and sea level rise threatens to expose 13 million people to flooding by 2100 (Reidmiller et al. 2018). Extreme events like Superstorm Sandy have revealed the inadequacies of how we calculate, map, and use knowledge about flood risks. National studies have shown that $25 \%$ of Federal Emergency Management Agency (FEMA) flood claims lay outside of the FEMA 100year flood zone (Blessing et al. 2017). Several studies report that population growth, gross domestic product (GDP), and climate change have all led to significant changes in flood exposure, and estimate that 41 million people-rather than the 13 million people shown in FEMA flood maps-live within the 100-year floodplain (Wing et al. 2018). It is clear that an upgrade, or even a rethinking, is urgently needed in how the United States maps and communicates risks of coastal floods.

In this chapter, we use the knowledge systems analysis framework as a lens to understand the social and technological challenges associated with coastal flood risk analysis, doing so with the objective of informing strategies and innovations needed to overcome those inadequacies. We refer to knowledge systems as the organizational practices and routines that produce, validate and review, communicate, and use knowledge relevant to policy and decision-making (Miller and MuñozErickson 2018; Muñoz-Erickson et al. 2017). Specifically, we conduct a knowledge system analysis of FEMA Flood Insurance Rate Maps (FIRMs) in New York City (NYC) - the largest coastal city of the Urban Resilience to Extremes Sustainability Research Network - to shed light on the social innovations required to make flood risk mapping work better for homeowners, businesses, and cities given our rapidly changing climate and urban landscapes. Cities are interested in improving their understanding of what are perceived to be the "true" or "real" risks of floods, so as to make and inform good decisions. What counts as a good estimate of such risks, however, is constructed through the design of a knowledge system that ratifies certain ideas and methods over others. Through this case study, we demonstrate the value of knowledge systems analysis as a method to stress-test and identify weaknesses and blind-spots that warrant attention. This analysis informs potential solutions to upgrade or redesign that system in support of building resilient cities.

\subsubsection{The National Flood Insurance Program}

The principal flood risk knowledge system in the United States is the FIRM produced by FEMA's National Flood Insurance Program (NFIP). FIRMs are also known simply as FEMA flood maps. The NFIP is responsible for generating knowledge about flood risk within defined zones, which in turn affects decisions about where and 
how homeowners and businesses build and the flood insurance rates they pay. The NFIP was created by the National Flood Insurance Act of 1968 and made federal flood insurance available for the first time (Michel-Kerjan 2010). The Flood Disaster Protection Act of 1973 made the purchase of flood insurance mandatory for those living within the boundaries of high-risk zones - the 100-year flood zone as defined by the NFIP (Michel-Kerjan 2010). The initial intent of the program was to provide immediate disaster relief to homeowners after experiencing a flood so they could get back on their feet and move out of the flood zone, ultimately reducing flood risk. Paradoxically, the NFIP instead disincentivized homeowners from moving out of flood-prone areas by shifting the costs to rebuild from the individual to society through heavily subsidized federal flood insurance (Platt 1999). Burby (2006) calls this phenomenon the safe development paradox. Unreliable flood maps (as discussed in this chapter) make this issue even worse when homes in high-risk flood zones are not properly identified and are therefore not required to carry federal flood insurance. As a result, the NFIP does not collect enough insurance premiums to cover its flood claims and has had to rely on tens of billions in government bailouts to remain afloat. Simply put, the NFIP system is broke and broken (Walsh 2017).

There have been several notable reforms to attempt to fix the NFIP. The 1994 Reform Act required FEMA to update its FIRMs every five years, though this policy has not been implemented diligently due to stressed budgets, limited administrative staffing, and appeals processes. The 2009 Department of Homeland Security Appropriations Act required FEMA to modernize flood maps by digitizing hand-drawn maps and updating FIRMs to reflect more recent historical climate data. The digitized maps were to be made publicly available through the FEMA Flood Map Service Center. The 2012 Biggert-Waters Flood Insurance Reform Act (BWFIRA) authorized FEMA to update the FIRM to include the best available scientific data regarding future intensities and frequencies of hurricanes, sea level change, precipitation, and storm surge (Grannis 2012). The BWFIRA attempted to raise insurance rates to reflect a property's "true" risk of flooding once a new flood map or update is producedeffectively eliminating the grandfathering process that was federally subsidizing risky properties with taxpayer money. The grandfathering process prevents owners of homes built before a map update from having to pay the full rate required by a new update. Instead, premiums increase over five years by just $20 \%$ per year. There was considerable backlash by flood insurance holders to the BWFIRA primarily due to the discontinuation of grandfathering. This political battle resulted in two additional bills which rolled back key provisions in the BWFIRA. The Consolidated Appropriations Act of 2014 prohibited FEMA from implementing Section 207 of the BWFIRA, which directed FEMA to use insurance rates commensurate with their full risk after a FIRM update. The 2014 Homeowner Flood Insurance Affordability Act restored the practice of grandfathering. 


\subsubsection{Flood Insurance Rate Maps as a Knowledge System}

Flood zones are demarcated by FEMA through a highly routinized process. Professional engineers use hydrodynamic modeling to calculate the expected height (i.e., base flood elevation or BFE) and location of floods by waterbodies such as rivers and oceans; the models do not consider floods from infrastructure failures, pluvial floods, or groundwater sources. For inland areas, flood zones and BFE are determined by modeling the overflow of water from streams that have exceeded their capacity during intense precipitation events (i.e., fluvial floods). In coastal areas, flood zones and the BFE are determined by several parameters: current sea level, wave setup, normal high tide, storm surge, and wave effects. Both fluvial and coastal flood modeling utilize digital elevation models (DEM) - typically derived from light detection and ranging (LiDAR) data-for determining the elevation profiles of the study area. The special flood hazard area (SFHA) — for both inland and coastal areas - is defined as the area exposed to a $1 \%$ annual exceedance probability (AEP) of experiencing a flood in any given year. This area is often referred to interchangeably by its return period - the amount of time between floods of a certain size. A flood with $\mathrm{T}$ year return period will have a $1 / \mathrm{T}$ probability of occurring in any given year (Lin et al. 2012; McPhillips et al. 2018). As such, the return period for an AEP of 1\% would be 100 years and the storm would be called a 100-year storm. The 100-year storm standard was selected as a compromise between two competing values: minimizing loss of life by restricting development in floodplains, and keeping floodplains open for economic and urban development (FEMA 2019a). The AEP is determined using statistical frequency analysis of past storms using historical weather data for fluvial floods, and synthetic storms (created from historical storm surge and tidal records, coastline profiles, and simulated laws of physics) for coastal floods (Sobel 2014). The SFHA determines the areas where flood insurance is required and where to enforce floodplain regulations. In addition to the SFHA, flood maps include the areas exposed to a $0.2 \%$ AEP storm (i.e., 500-year flood) for reference only. The teal- and black-dotted zones on a FIRM demarcate the 100-year and 500-year flood zones, respectively (see Fig. 5.1). A common criticism of this system is that flood risk for a property is often misconstrued as binary-a property is either in a flood zone or out of it (Kousky 2018). The 500-year flood zone line on flood maps creates this false sense of security on the other side of that line. To make matters worse, FEMA's terminology of a 100-year or 500-year flood zone is also misinterpreted by those who are actually aware that they are in one of those flood zones. For those living in a 100-year flood zone, the message received is that their property will only flood once in 100 years when, in reality, FEMA is trying to communicate that the risk is a $1 \%$ probability of flooding every year (FEMA 2017). For instance, over the course of a 30 -year mortgage, a property has a $26 \%$ chance of flooding. However, as shown throughout this chapter, that is not the "real" risk either. 


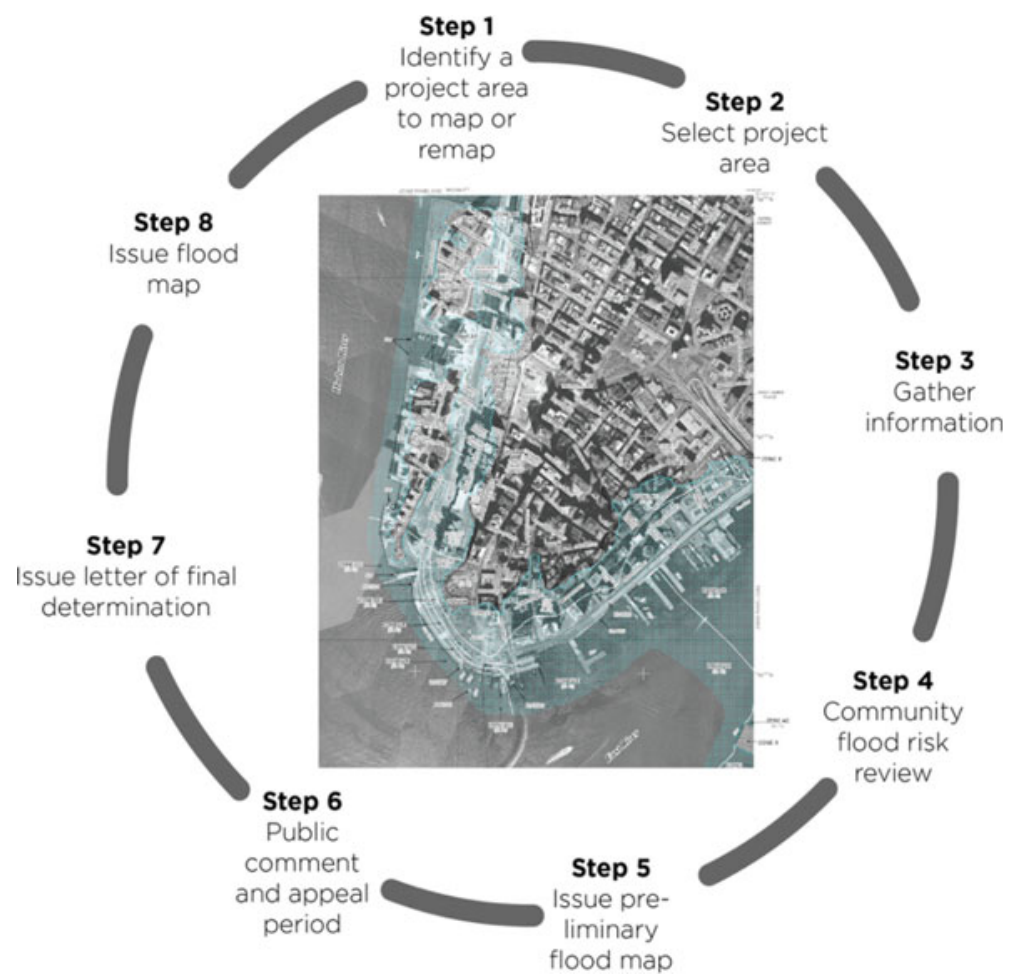

Fig. 5.1 The process for creating a Federal Emergency Management Agency (FEMA) flood map. The current regulatory FEMA Flood Insurance Rate Map for lower Manhattan is shown in the center of the figure. Adapted from FEMA (2019a). Lower Manhattan FIRM courtesy of the FEMA Flood Map Service Center (FEMA nd)

FEMA flood maps are the product of an eight-step iterative process (Fig. 5.1) that begins by identifying a project area (Step 1), deciding on a watershed to map or remap (Step 2), and gathering technical data such as hydrological, infrastructural, land use, and population data (Step 3). A Flood Insurance Study is produced and then shared with community officials to review and provide feedback (Step 4). Once the preliminary FIRM is issued (Step 5), the FIRM can be amended or revised through individual or community appeals (Step 6; FEMA 2019b). Individual property owners can submit a Letter of Map Amendment to provide data showing that their property is not within the SFHA. Community officials can submit a Letter of Map Revision (LOMR) using new scientific or technical data to revise a flood map. Both the LOMA and the LOMR do not actually lead to a physically revised flood map-the changes are documented in letter format only. The Chief Executive Officer (CEO) of a community is the only person who can submit a Physical Map Revision (PMR) to FEMA to physically change the flood zones on a FIRM. Both the PMR and LOMR are typically prepared by experts contracted by local governments. As such, these revisions are costly and resource-intensive endeavors. Once the appeals period 
expires, a letter of final determination is sent to notify the CEO that the community has six months to adopt a compliant floodplain management ordinance (Step 7) before the new regulatory FIRM becomes effective (Step 8). The case study presented in this chapter will analyze the production, revision, validation, communication, and use of FEMA maps in NYC since 1981.

\subsubsection{Knowledge Systems Analysis}

looseness-1Knowledge systems analysis is a useful framework to explore the underlying ideas, rationales, social practices, and institutional structures that define sustainability, resilience, and environmental problems. The framework has been applied to analyze a variety of socio-environmental issues, including sustainability visions (Muñoz-Erickson 2014), green infrastructure (Matsler 2017), cloudburst flood resilience (Rosenzweig et al. 2019), integration of citizen and technical flood risk knowledge (Ramsey et al. 2019), and the scalar politics of coastal flood risk (Rozance et al. 2019).

Like systems in general, knowledge systems are described in terms of the functions, elements, and complexities of the systems (Miller and Muñoz-Erickson 2018). The core functions of a knowledge system include the production, validation, review, communication, and use of knowledge. For our FEMA case, the process of developing the FEMA flood map is what defines this knowledge system. The steps shown in Fig. 5.1 reflect the various actors involved in how this knowledge system works, including the production of the flood map by FEMA engineers and city leaders (Steps 1 to 3), the review and validation of the maps by local community leaders (Steps 4, 6, and 7), its communication through the issuing of the preliminary FIRM (Step 5) and regulatory FIRM (Step 8), and its use in decision-making processes as to where to build, how high to build, and what flood insurance rates to charge homeowners. Elements of a knowledge system include the content of that knowledge (including its associated uncertainties), the values embedded in that knowledge, the epistemologies (or how we know what we know), and the institutional structures (people and organizations) through which knowledge is constructed and put to use. For the FIRM, knowledge consists of the actual flood maps that are produced and the knowledge claims that are made regarding those maps (e.g., homes in the FEMA 100-year flood zone have a $1 \%$ rate of flooding in any given year). Values may include how the knowledge system prioritizes urban and economic development versus restricting development in flood zones, decisions to set risk boundaries in terms of specific flood return periods (e.g., 100-year and 500-year flood zones), and decisions about how to balance historical data and future projections in setting risk zone boundaries. Epistemologies refer to how the problem is framed, types of evidence (e.g., rainfall data from the past 50 years, LiDAR satellite data, etc.), and the information technologies (e.g., hydrological models) used to produce flood maps. Structures include actors or stakeholders that are involved in the functions of the knowledge system. Analyzing knowledge system structures often reveals how power and authority are 
distributed and the consequences that these arrangements have on the production, communication, and use of knowledge (Muñoz-Erickson and Cutts 2016; MuñozErickson et al. 2017; Ramsey et al. 2019). The role of power and authority in the operations of the FEMA flood map knowledge system in NYC will also be explored in the next section.

\subsection{New York City Flood Map Case Study}

Our city needs precise flood maps that reflect real risks, both today and years from now, and we have to do that fairly-NYC Mayor Bill de Blasio

To conduct the knowledge system analysis of FEMA flood maps for the NYC case study, we use the framework outlined above to review official FEMA products and documents, reports, academic publications, and newspaper articles containing accounts by various types of flood map users. The above quote by Mayor de Blasio highlights the main aspirations and challenges with flood risk mapping in NYC and the nation. City governments value accurate maps that reflect the "real" risks of floods and communicate reliable information about future flood risk to the public. Yet, city governments also wish to have this risk analysis done in a way that does not place unnecessary burdens on homeowners (e.g., higher insurance premiums or decreased home values) or slow down local economic growth (due to restrictions on development in ever-expanding flood zones). The technical flood mapping process is performed within this negotiation of values and risk tolerance. As such, flood maps are more than just technical products-they are maps with great social implications that warrant care in how they are produced so as to not disproportionally or inappropriately impact any particular social group or sector. At the same time, many hurdles must be overcome in efforts to include future flood risks into FEMA flood map products due to the large uncertainties inherent in future climate and sea-level projections. Through this case study, we use knowledge system analysis to illustrate both the technical and socio-political processes - spanning almost four decades (see Fig. 5.2) - that went into the production, validation, communication, and use of FIRMs in NYC, and the implications this has for resilience to extreme flood events.

Superstorm Sandy, which made landfall in NYC on Oct 29, 2012, was one of the worst natural disasters the city has experienced. Sandy was responsible for $\$ 19$ billion in losses and 43 deaths throughout New York, as well as $\$ 65$ billion in losses and 159 deaths nationwide (PlaNYC 2013). Sandy's storm surge of $14+$ feet (ft) left parts of NYC in ruins and nearly two million residents without power for up to two weeks (PlaNYC 2013).

The damage from Sandy resulted from a storm surge that was the highest in the historical tide gauge record-extending as far back as 1850 - and exacerbated by a seasonal high tide that inundated areas well beyond FEMA flood zones. As seen in Fig. 5.3, sea level rise also played a small but significant role in contributing to 


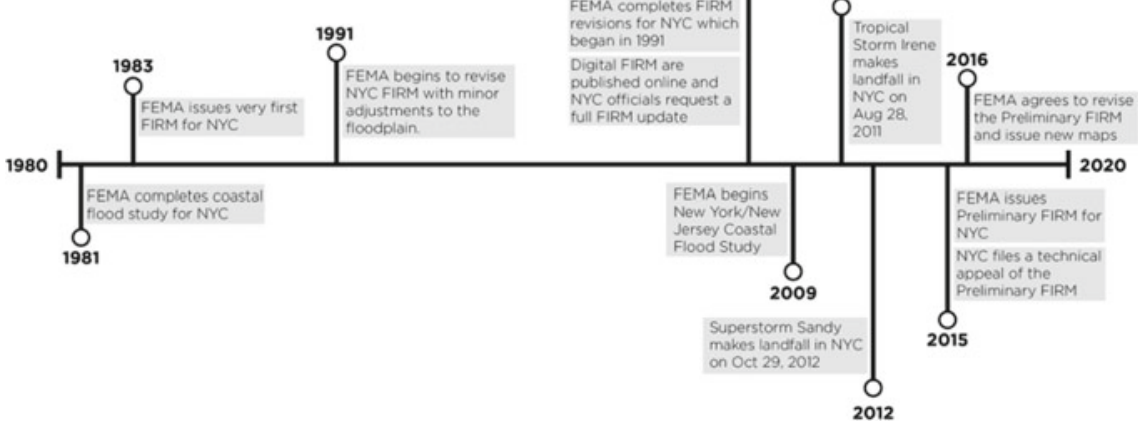

Fig. 5.2 Timeline of Federal Emergency Management Agency flood map production for New York City. Adapted from PlaNYC (2013)

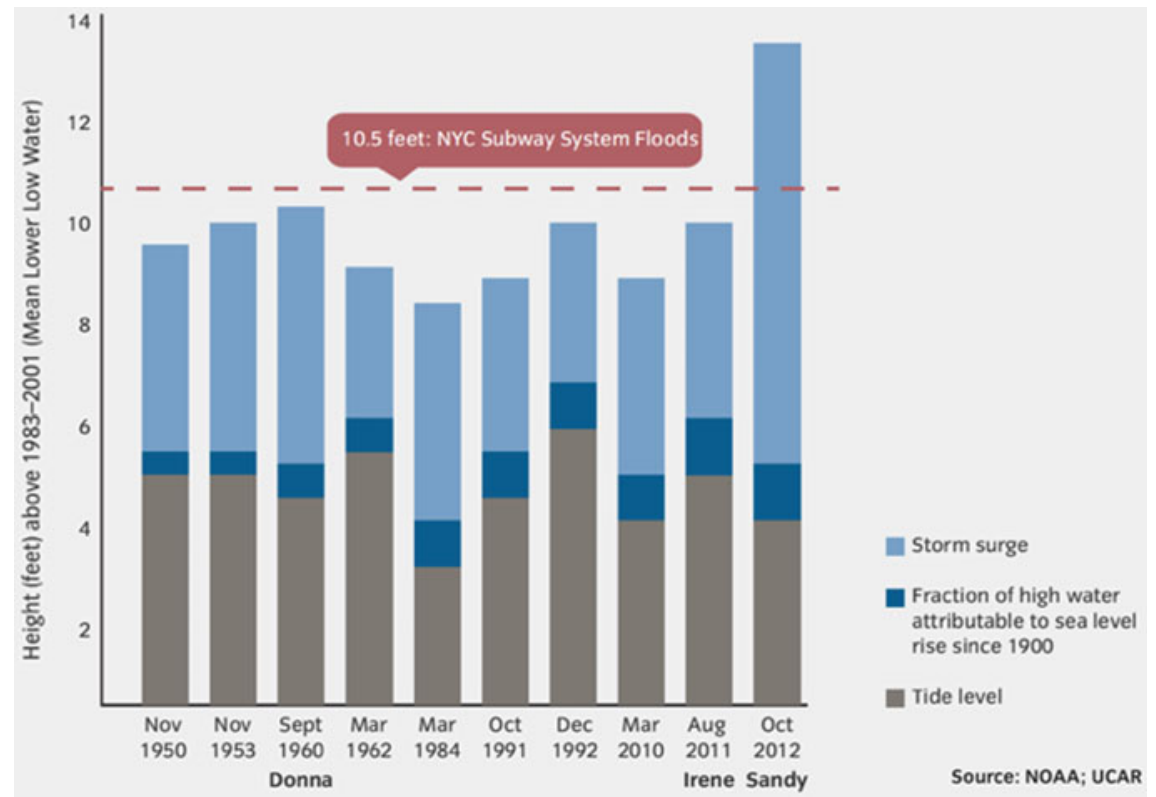

Fig. 5.3 Historical high-water events in lower Manhattan. Used with permission of the New York City Department of City Planning. All rights reserved

the record flood height. At the time of Sandy's landfall, the flood maps were grossly outdated - they did not reflect changes in climate and sea levels (see Fig. 5.4), rapid land-use change, or advances in technology such as the development of more accurate elevation profiles from LiDAR (Parris 2014).

The regulatory flood maps for NYC have not received a significant update since 1983, despite the legal requirement for flood maps to be updated every five years. 


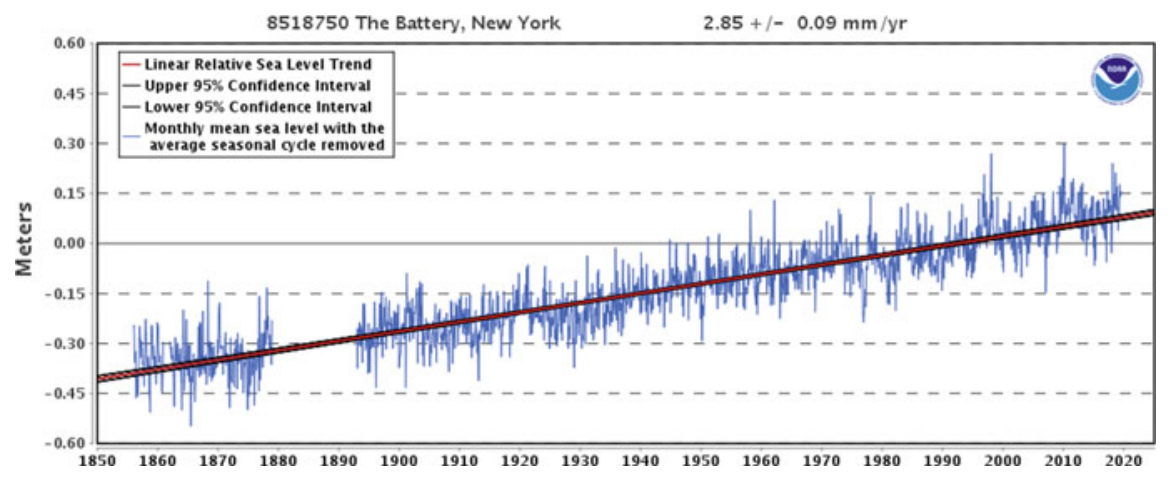

Fig. 5.4 Relative sea level trend as measured from The Battery tide gauge station in NYC. Plotted values are monthly averages. The historic rate of sea level rise is $2.85 \mathrm{~mm} /$ year, or about 1 foot every 100 years (National Oceanic and Atmospheric Administration 2019)

From 1991 to 2007, flood map updates included new wetland and stream modeling but failed to include any elevation adjustments. In effect, these were very minor modifications to the original 1983 floodplains. The results were placed on satellite imagery, digitized, and made available online for general public consumption in 2007. Concerned about the inaccurate flood risk information being communicated to the public, local and state officials immediately called on FEMA to perform a full map update using the best scientific data and technology available. The update process did not begin until 2009 and had yet to be completed before Sandy struck in October of 2012 (see Fig. 5.2 timeline).

The 2007 FIRM underestimated the scope of inundation that awaited the city during Sandy. Only 54 and $47 \%$ of the flooded area in Queens and Kings, respectively, was predicted by the 1983 flood maps during Sandy (Shaw et al. 2013). Figure 5.5 shows the vast swaths of the city inundated by Sandy, yet left out from the 1983 FIRM 100-year floodplain. However, Sandy was not calculated to be a 100-year storm; it was estimated by using outdated historical climate data to be a 1,000-year storm (Lin et al. 2012). However, several authors argue that climate change helped to intensify Superstorm Sandy (Dietrich 2017; Parris 2014; Sobel 2014). Increases in sea levels alone could have accounted for half a foot of flooding during Sandy (Parris 2014; Shaw et al. 2013). Lin et al. (2012) show that when taking into consideration changing climate and increasing sea levels, the current 100-year storm surge event in NYC has the potential to occur every 20 years or less and the present 500 -year event has the potential to occur every 240 years or less by 2100 . Thus, there are strong reasons to update flood maps regularly to reflect changing climate and sea levels. If the FEMA flood maps had been updated prior to Sandy to incorporate recent SLR and extreme precipitation and flooding events (e.g., the March 2010 nor'easter and Tropical Storm Irene in 2011), they may have more accurately reflected the extent of flood risk during Sandy and improved flood risk communication and resilience outcomes. 


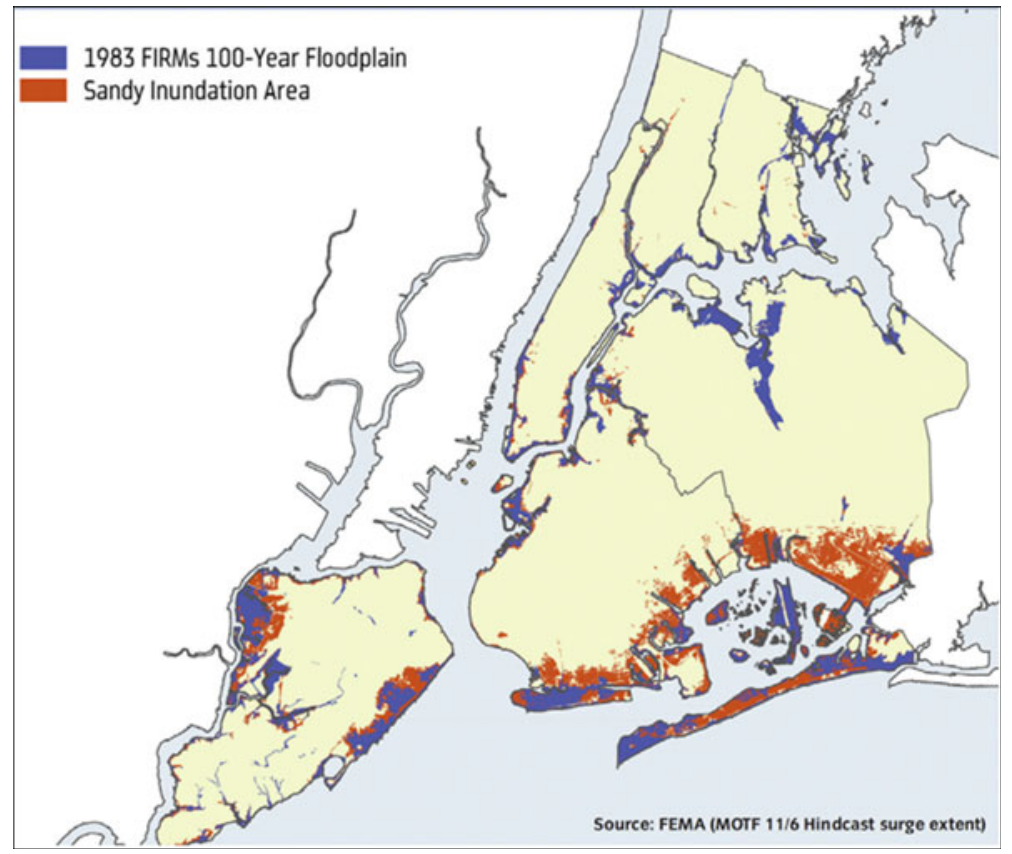

Fig. 5.5 1983 federal emergency management agency flood insurance rate map and Sandy inundation area comparison (PlanNYC 2013). Image used with permission of the New York City Department of City Planning. All rights reserved

After completing the Coastal Flood Study for New York in 2009, FEMA issued the 2015 Preliminary FIRM (P-FIRM) for NYC using new LiDAR data, more recent climatological data (e.g., Tropical Storm Irene and Superstorm Sandy were both included), and more sophisticated hydrologic modeling. The 2015 P-FIRM nearly doubled the building stock located in the 100-year flood zone from 36,000 to 71,500 units (City of New York Mayor's Office of Recovery and Resiliency 2015). Nearly twice as many New Yorkers would be required to pay for mandatory flood insurance after this update. The P-FIRM had the potential to aggravate the affordable housing crisis in NYC by expanding the reach of mandatory flood insurance and increasing existing premiums (Dixon et al. 2017). Consequently, the news was not welcomed by affected homeowners (Chen 2018). Under public pressure to keep housing and insurance rates affordable, NYC pushed back by filing an appeal of the 2015 P-FIRM on scientific and technical grounds (Chen 2018). The City's appeal was politically motivated, but had to be filed on scientific and/or technical grounds-FEMS's epistemology for creating and revising flood maps. As discussed in the section entitled "Flood Insurance Rate Maps as Knowledge Systems," the Chief Executive Officer of a community has the sole legal authority to challenge FEMA's flood mapping expertise. The appeal must also be submitted within a 90-day period after a PFIRM is issued. The New York City Mayor's Office contracted outside engineering 
firms, which included the design and consultancy firm Arcadis, to conduct the City's flood analysis. NYC's appeal claimed that scientific and technical errors-insufficient extratropical storm model validation and misrepresentation of tidal effects of extratropical storms - lead to the P-FIRM overstating the BFE by over $2 \mathrm{ft}$ in many areas and presenting 35\% larger SFHA boundaries (City of New York Mayor's Office of Recovery and Resiliency 2015). However, NYC elsewhere claimed that the initial reason for the appeal was that "the revisions will assist New York City in making coastlines more resilient and climate ready, while ensuring homeowners are not required to purchase more insurance than their current flood risk requires" (City of New York nd). The appeal was an attempt to reduce the extent of the new SFHA and BFE in the P-FIRM (the political goal) while also updating the maps with more recent climate and storm data (the resiliency goal). Rather than 71,500 buildings in the SFHA, the new NYC analysis reduced the number of units to just 45,000 - a $37 \%$ reduction - as shown on the P-FIRM. The appeal also provided extra time before an update could be issued-effectively saving property owners money as their insurance rates and requirement to purchase flood insurance would continue to be based on the 2007 FIRM SFHA boundaries. The City's appeal was successful. FEMA agreed in 2016 to revise the maps according to the City's analysis. However, as of December 2019, FEMA has still not issued any update to NYC's FIRM. As such, there are now three competing knowledge claims regarding claims regarding New Yorkers' FEMA-delineated flood risk, leaving residents in limbo regarding this risk (e.g., the current regulatory 2007 FIRM, the 2015 Preliminary FIRM, and NYC's flood analysis). While the City's political goal may have been achieved through this appeal, this state of uncertainty is a failure of the flood mapping knowledge system to clearly, timely, and definitively communicate flood risk to property owners for their individual resilience and adaptation decisions. For instance, a prospective homebuyer may unknowingly become vulnerable to floods by purchasing a new home that is within the SFHA on NYC's flood analysis, but does not fall within this zone according to the 2007 FIRM - the map currently used to determine flood risk for a property. For instance, many residents of Staten Island-one of the hardest hit places during Sandy - expressed frustration that they did not know their properties were at risk of flooding at the time they purchased their homes (Moore 2018). The Morgan family-whose basement was destroyed in Sandy-said they would have at least moved their utilities out of the basement had they known Sandy was predicted to bring $11 \mathrm{ft}$ of flooding-as shown on the P-FIRM-compared to the less than $1 \mathrm{ft}$ shown on the 2007 FIRM (Shaw et al. 2013).

In contrast, there is actually a clear and definitive standard for resolving these competing flood risk knowledge claims for use in building construction at the city level. NYC adopted Local Law 96/13 which modified the City's building code to require all work permits for construction projects to be based on the more restrictive BFE and SFHA of either the 2007 FIRM or the P-FIRM (NYC Buildings 2014). Additionally, the NYC Commissioner of Buildings issued a rule in 2013 that for buildings in the SFHA, 1 to $2 \mathrm{ft}$ must be added to the BFE in order to determine the Design Flood Elevation (DFE). No dwelling units or mechanical equipment (e.g., electrical and HVAC systems) are permitted in floors below the DFE (New York City 
Planning Department 2013). By decoupling the P-FIRM from insurance rate hikes, NYC was able to make use of this valuable knowledge for construction decisions without imposing new or higher flood insurance costs on residents.

While the P-FIRM and NYC's flood analysis incorporated more recent climate data, these maps still do not incorporate any anticipated future flood risk (e.g., sea level rise) for long-term residential or urban planning decisions. NYC addressed this knowledge gap in 2008 by creating a new knowledge system separate from the NFIP. The New York Panel on Climate Change (NPCC) is a panel of experts created by the NYC Mayor's Office to provide analysis of future climate change impacts such as extreme floods. FEMA is now collaborating with the NPCC to create "innovative, climate-smart flood maps" for NYC that incorporate the best available science regarding future sea levels and coastal storms for long-term planning and building purposes, while updating the FIRM to depict current risk for insurance purposes (FEMA 2016). The NPCC recently published its projections of NYC's floodplain for 2100 and compared it to the 2015 P-FIRM (Patrick et al. 2019). The results indicate that the floodplain is likely to expand as NYC experiences additional sea level rise and more intense storm surges (Fig. 5.6).

The NPCC's anticipatory flood maps are not yet required for NYC's long-term planning decisions, but the City now has access to this valuable knowledge. While the NPCC has been helpful for the City to understand their future flood risk, individual New Yorkers are still largely in the dark. NYC has recently created a new position, Deputy Director of Climate Science and Risk Communication, to serve as a City liaison to the NPCC. There is hope that the creation of this new position may help communicate the NPCC's forward-looking flood risk maps to the general public.

The strategy of decoupling flood risk knowledge from insurance rates is at the core of this knowledge innovation for anticipatory flood resilience decision-making in NYC. Access to resources-money and experts-were also essential. NYC had the resources to convene the expert NPCC panel to produce this knowledge for the City's planning and decision-making. Yet, few cities have NYC's financial and university resources to be able to create an entirely new knowledge system-such as the NPCC - to augment the inadequate FEMA flood maps. From a social justice and equity perspective, it is important that FEMA step in to provide access to futurelooking flood risk knowledge for resource-scarce cities. However, there is not a clear path forward for how FEMA will communicate future risks of flooding for community resilience and adaptation decisions. FEMA has been authorized to provide maps of future flood risk since the BWFIRA was enacted in 2012. However, the FEMA Technical Mapping Advisory Council's efforts have been stalled and their final report withheld, preventing legally binding guidance on how FEMA should move forward with communicating future flood risks. In the following section, we discuss some possible options for redesigning the NFIP based on this knowledge system analysis of NYC flood risk mapping. 


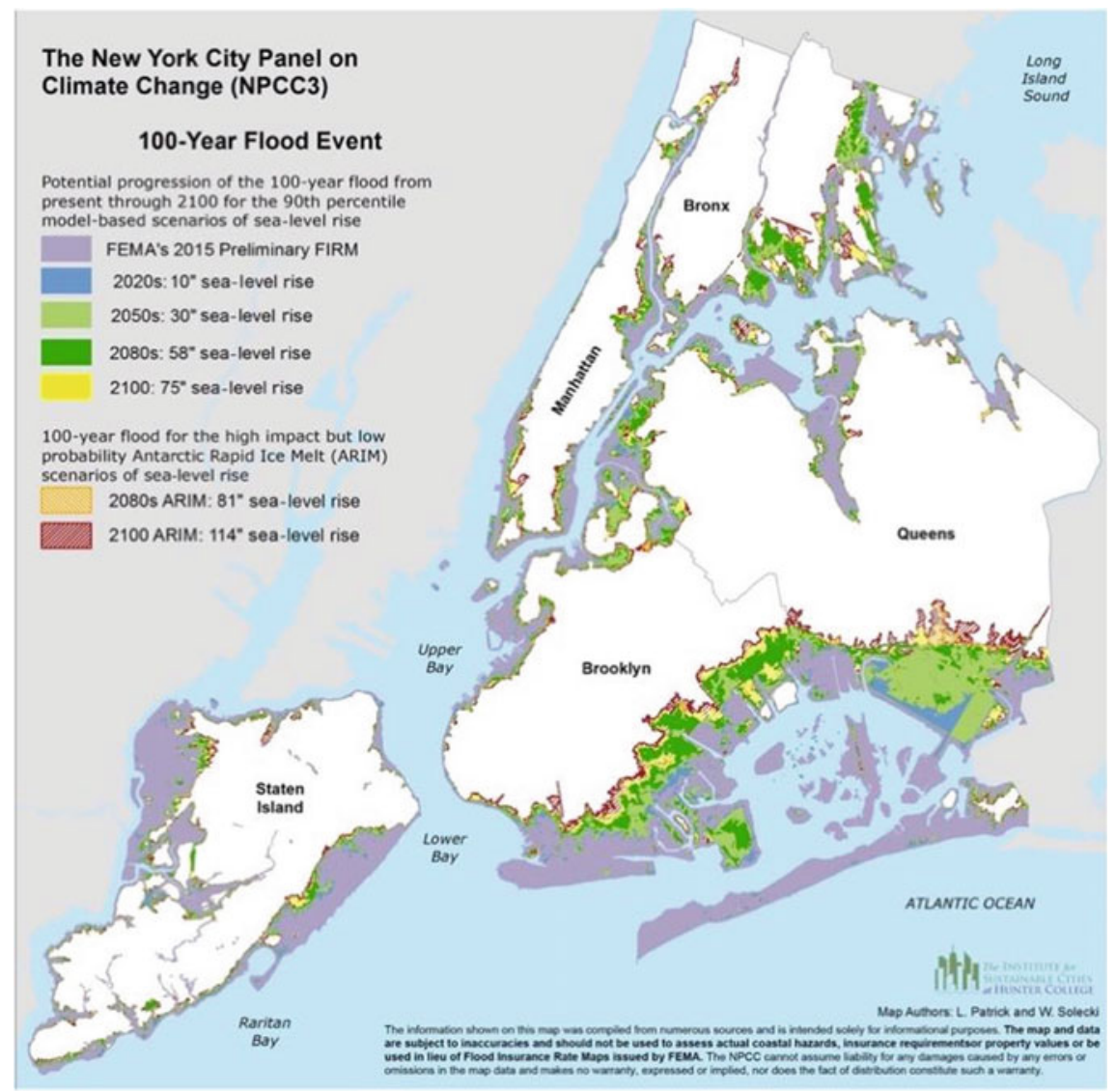

Fig. 5.6 Projected 100-year floodplain through 2100, as compared to the 2015 Preliminary Flood Insurance Rate Map (Patrick et al. 2019)

\subsection{Discussion and Conclusion}

Understanding how the FEMA flood map knowledge system works is essential for the adaptive capacity and resilience of cities to climate change and extreme events. These maps guide a myriad of important decisions affecting urban form and community resilience both now and in the long-term future. Homeowners use this information to make individual decisions such as whether to buy a home, carry flood insurance for a home, how high to elevate a home, or simply whether or not to move a generator or other appliances out of their basement or ground floor. Developers use this information to decide where to build and the design of the building. City engineers use this information to determine where and how to build critical infrastructure throughout the city. As the U.S. Department of Homeland Security Office of the 
Inspector General (DHS OIG 2017) reported, it is imperative that we provide accurate and reliable flood risk information to the public, and this will require changes to the flood mapping process, management, and oversight. In essence, the DHS is calling for a knowledge system upgrade or redesign to modernize the flood mapping process given its expanded user network and salience.

As we have shown with the NYC case study, the FEMA flood map knowledge system has several social-political and technical challenges associated with it, including outdated climate data, lack of anticipatory flood risk knowledge, difficult to interpret and communicate flood risks, lack of consideration of infrastructure or pluvial floods, politically motivated map revisions, a resource-intensive and inequitable revision process, and so on. How well a knowledge system produces quality knowledge for decision-making is not simply a matter of collecting the best scientific data and using the most sophisticated technology to produce a flood map; the distribution of power and authority also greatly influences the quality and accuracy of the knowledge claims produced by the knowledge system (e.g., the SFHA boundaries and BFE of the P-FIRM and NYC flood analyses). In NYC, the social (e.g., the formalized and routinized process of creating map products) and political (e.g., who wins and who loses from map updates, who has authority to challenge flood map knowledge claims, etc.) dynamics have played key roles in the production, review and validation, communication, and use of flood maps over the past four decades. Any redesign will need to address both the social-political and technical aspects of this knowledge system.

You might ask, what would an upgraded or redesigned flood mapping system look like and how could it be accomplished? The low-hanging fruit for an upgrade would be for FEMA to include non-regulatory future flood risk knowledge alongside their official regulatory map products; this would effectively decouple this information from determining insurance rates. As shown in the NYC case study, by decoupling the P-FIRM from insurance rates, NYC was able to use this valuable knowledge for building construction and zoning decisions to improve the long-term flood resilience of the City's built environment. A more transformative change to the entire flood mapping system would be to retire the use of the 100-year and 500-year flood zones given the well-documented misconceptions users have and the false sense of security they give to residents living outside of these zones. This technical change will also be inherently disruptive socio-politically as new federal legislation would need to be written and the entire NFIP — which provides disaster relief to flood victims - would need to be dramatically revised to accommodate this change. This redesign would likely require new legislation from the U.S. Congress. It would also likely require a shift in the values underpinning the knowledge system-which are notoriously difficult to change. Given the magnitude of recent flood disasters like Hurricane Katrina, Superstorm Sandy, Hurricane Harvey, and Hurricane María, it may become necessary to value the protection of lives and property more than is currently done relative to the value accorded to urban development and growth. The Special Hazard Flood Area-which restricts development in the 100-year flood zone-was chosen as a balance between these two values. The NFIP may require a recalibration of our nation's flood risk tolerance and values in order to fix this broken and broke program. 
In closing, our analysis of how the FEMA FIRM knowledge system works sheds light on the underlying complex social and political dynamics involved in how we know, review and validate, communicate, and use flood risk knowledge. Knowledge about flood risks is more than the map that results from collecting data and running models to determine "real" flood risk for a property; it is the outcome of a highly contested co-production process between individual residents, experts (e.g., engineers and hydrologists), city officials, federal government agencies, and other stakeholders as they seek to map flood risk while trying to achieve their diverse and conflicting goals (e.g., minimizing flood insurance costs while improving the accuracy of flood maps). Many important technological innovations are being developed to improve how we calculate flood risks, including, for instance, advances in real-time flood sensor systems, sophisticated hydrological models, and use of highresolution satellite data. These innovations will fall short, however, if they don't also address the non-technical and social aspects crucial to making knowledge systems work. In light of accelerated climate change and extreme coastal events, we suggest that more attention toward understanding flood risk as a knowledge systems problem can further advance resiliency goals for coastal cities.

Acknowledgements This material is based upon work supported by the National Science Foundation-funded Urban Resilience to Extreme Weather-Related Events Sustainability Research Network (UREx SRN; NSF grant no. SES 1444755), as well as dissertation research grants provided to Robert Hobbins from the Graduate Professional Student Association at Arizona State University and the American Association of Geographers. The authors are also very grateful for the time and information provided by practitioners in our case study cities and from the two anonymous reviewers who provided valuable feedback on earlier versions of this chapter.

\section{References}

Blessing R, Sebastian A, Brody SD (2017) Flood risk delineation in the U.S.: How much loss are we capturing? Nat Hazard Rev 18(3):1-10. https://doi.org/10.1061/(ASCE)NH.1527-6996.000 0242

Burby RJ (2006) Hurricane Katrina and the paradoxes of government disaster policy: Bringing about wise governmental decisions for hazardous areas. Ann Am Acad Political Soc Sci 604(1):171191. https://doi.org/10.1177/0002716205284676

Chen DW (2018) In New York, drawing flood maps is a "game of inches." https://www.nytimes. com/2018/01/07/nyregion/new-york-city-flood-maps-fema.html. Accessed 01 Nov 2019

City of New York Mayor's Office of Recovery and Resiliency (2015) Appeal of FEMA's preliminary flood insurance rate maps for New York City. https://www1.nyc.gov/assets/floodmaps/images/ content/pages/1-NYC\%20FEMA\%20Appeal\%20FINAL\%20with\%20Appendices\%20and\% 20Cover\%20Letter\%2006252015_web.pdf. Accessed 15 Dec 2019

City of New York (nd) Appeals. NYCFlood Maps. https://www1.nyc.gov/site/floodmaps/appeals/ overview.page. Accessed 11 Nov 2019

Dietrich JC (2017) Vignette: climate change effects on flooding during Hurricane Sandy. In: Horney J (ed) Disaster epidemiology: methods and applications, 1st edn. Academic Press, Cambridge, MA, pp 153-156 
Dixon L, Clancey N, Miller B et al (2017) The cost and affordability of flood insurance in New York City: economic impacts of rising premiums and policy options for one- to four-family homes. https://www.rand.org/pubs/research_reports/RR1776.html. Accessed 14 Dec 2019

Federal Emergency Management Agency (2016) Mayor De Blasio and FEMA announce plan to revise NYC'sflood maps. https://www.fema.gov/news-release/2016/10/17/mayor-de-blasio-andfema-announce-plan-revise-nycs-flood-maps. Accessed 11 August 2019

Federal Emergency Management Agency (2017) FEMA fact sheet: common questions about flood maps and risk. https://www.fema.gov/media-library-data/1513200364180-bab79b0ae4855f62eb c94baa06fc0186/Common_Questions_Fact_Sheet.pdf. Accessed 14 Dec 2019

Federal Emergency Management Agency (2019a) The Risk MAP flood riskproject lifecycle. Department of Homeland Security. https://www.fema.gov/risk-map-flood-risk-project-lifecycle. Accessed 14 Dec 2019

Federal Emergency Management Agency (2019b) Flood map revision process. https://www.fema. gov/flood-map-revision-processes. Accessed 14 Dec 2019

Federal Emergency Management Agency (nd) FEMA flood map service center. Department of Homeland Security. https://msc.fema.gov/portal/search?AddressQuery=lower\%20manhattan\# searchresultsanchor. Accessed 14 Dec 2019

Grannis J (2012) Analysis of how the flood insurance reform act of 2012 (H.R. 4348) may affect state and local adaptation efforts. Georgetown Climate Center. https://www.georgetownclimate. org/files/report/Analysis\%20of\%20the\%20Flood\%20Insurance\%20Reform\%20Act\%20of\% 202012.pdf. Accessed 11 Aug 2019

Kousky C (2018) How America fails at communicating flood risks. City Lab. https://www.citylab. com/environment/2018/10/how-america-fails-communicating-flood-risks/572620/. Accessed 11 Aug 2019

Lin N, Emanuel K, Oppenheimer M et al (2012) Physically based assessment of hurricane surge threat under climate change. Nat Clim Change 2(6):462-467. https://doi.org/10.1038/nclima te 1389

Matsler AM (2017) Knowing nature in the city: comparative analysis of knowledge systems challenges along the eco-techno spectrum of green infrastructurein Portland \& Baltimore. Dissertation, Portland State University

McPhillips LE, Chang H, Chester M et al (2018) Defining extreme events: a cross-disciplinary review. Earth's Future 6(3):441-455. https://doi.org/10.1002/2017EF000686

Michel-Kerjan EO (2010) Catastrophe economics: the national flood insurance program. J Econ Perspect 24(4):165-186. https://doi.org/10.1257/jep.24.4.165

Miller C, Muñoz-Erickson T (2018) The rightful place of science: designing knowledge. Consortium for Science, Policy \& Outcomes, Phoenix

Moore R (2018) For Sandy survivors this program made all the difference. https://www.nrdc.org/ experts/rob-moore/title. Accessed 14 Dec 2019

Muñoz-Erickson TA (2014) Multiple pathways to sustainability in the city: The case of San Juan, Puerto Rico. Ecol Soc 19(3). https://doi.org/10.5751/ES-06457-190302

Muñoz-Erickson TA, Cutts BB (2016) Structural dimensions of knowledge-action networks for sustainability. Curr Opin Environ Sustain 18:56-64. https://doi.org/10.1016/j.cosust.2015.08.013

Muñoz-Erickson TA, Miller CA, Miller TR (2017) How cities think: knowledge co-production for urban sustainability and resilience. Forests 8(6):1-17. https://doi.org/10.3390/f8060203

National Oceanic and Atmospheric Administration (2019) Relative Sea Level Trend, 8518750 The Battery, New York. NOAA Tides and Currents. https://tidesandcurrents.noaa.gov/sltrends/ sltrends_station.shtml?id=8518750. Accessed 13 Nov 2019

New York CityPlanning Department (2013) Coastal climate resilience: Designing for flood risk. www.nyc.gov/designingforfloodrisk. Accessed 11 Nov 2019

NYCBuildings (2014) Recently enacted resiliency legislation. https://www1.nyc.gov/assets/buildi ngs/pdf/summary_resiliency_legislation.pdf. Accessed 11 Nov 2019

Parris A (2014) How Hurricane Sandy tamed the bureaucracy. Issues Sci Technol 30(4):83-90 
Patrick L, Solecki W, Gornitz Vet al (2019) Chapter 5: mapping climate risk. In: Rosenzweig C, Solecki W (eds) New York City panel on climate change2019 report. Annals of the New York Academy of Science, New York City, pp 115-125. https://doi.org/10.1111/nyas.14015

PlaNYC (2013) A stronger, more resilient NYC. City of New York. https://www1.nyc.gov/site/sirr/ report/report.page. Accessed 14 Aug 2019

Platt RH (1999) Disasters and democracy: the politics of extreme natural events, 2nd edn. Island Press, Washington, DC

Ramsey MM, Muñoz-Erickson TA, Mélendez-Ackerman E et al (2019) Overcoming barriers to knowledge integration for urban resilience: a knowledge systems analysis of two flood prone communities in San Juan, Puerto Rico. Environ Sci Policy 99:48-57. https://doi.org/10.1016/j. envsci.2019.04.013

Reidmiller DR, Avery CW, Easterling, DR et al (2018) Fourth national climate assessment. https:// nca2018.globalchange.gov/chapter/front-matter-about/. Accessed 11 Aug 2019

Rosenzweig B, Ruddell BL, McPhillips L et al (2019) Developing knowledge systems for urban resilience to cloudburst rain events. Environ Sci Policy 99:150-159. https://doi.org/10.1016/j.env sci.2019.05.020

Rozance MA, Denton A, Matsler M (2019) Examining the scalar knowledge politics of risk within coastal sea level rise adaptation planning knowledge systems. Environ Sci Policy 99:105-114. https://doi.org/10.1016/j.envsci.2019.05.024

Shaw A, Thompson C, Meyer T (2013) Federal flood maps left New York unprepared for Sandyand FEMA knew it. ProPublica. https://www.propublica.org/article/federal-flood-maps-left-newyork-unprepared-for-sandy-and-fema-knew-it. Accessed 11 Nov 2019

Sobel AH (2014) Storm surge. HarperCollins, New York

U.S. Department of Homeland Security Office of the Inspector General (2017) FEMA needs to improve management of its flood mapping programs. https://www.oig.dhs.gov/sites/default/files/ assets/2017/OIG-17-110-Sep17.pdf. Accessed 11 Aug 2019

Walsh MW (2017) A Broke, and broken, flood insurance program. New York Times. https://www.nyt imes.com/2017/11/04/business/a-broke-and-broken-flood-insurance-program.html. Accessed 11 Aug 2019

Wing OEJ, Bates PD, Smith AM et al (2018) Estimates of present and future flood risk in the conterminous United States. Environ Res Lett 13(034023):1-7. https://doi.org/10.1088/17489326/aaac65

Robert Hobbins is a Ph.D. Candidate at the School of Sustainability at Arizona State University and an NSF Research Intern at the USDA Forest Service International Institute of Tropical Forestry. Robert has a BS in Physics and a Master of Education from The Ohio State University. He also earned an MS in Community Resources \& Development-Sustainable Communities at Arizona State University. Robert joined the Urban Resilience to Extremes Sustainability Research Network (UREx SRN) as a Graduate Fellow in 2016 and continues to be active in the network by supporting the planning and implementation of scenario workshops and working with UREx SRN city practitioners to build local capacities to transition to more sustainable and resilient urban futures.

Tischa A. Muñoz-Erickson is a Research Social Scientist in the USDA Forest Service's International Institute of Tropical Forestry, in Río Piedras, Puerto Rico. She studies urban sustainability governance, including the policy networks, knowledge systems, anticipatory capacities, and strategies to advance sustainability, resilience, and equity. She is also actively involved in transdisciplinary platforms to facilitate the co-production of futures and transition pathways in the US and Latin American cities. Muñoz-Erickson leads the International Urban Field Station and the San Juan ULTRA and is also Co-PI of the National Science Foundation Urban Resilience to Extreme Events Sustainability Research Network (UREx SRN) and the SETS Convergence project. 
Clark Miller is Professor and Director of the Center for Energy and Society in the School for the Future of Innovation in Society at Arizona State University. His work offers theoretical, practical, and critical insights into how societies can better design and deploy knowledge and technology in the service of more just and sustainable futures.

Open Access This chapter is licensed under the terms of the Creative Commons Attribution 4.0 International License (http://creativecommons.org/licenses/by/4.0/), which permits use, sharing, adaptation, distribution and reproduction in any medium or format, as long as you give appropriate credit to the original author(s) and the source, provide a link to the Creative Commons license and indicate if changes were made.

The images or other third party material in this chapter are included in the chapter's Creative Commons license, unless indicated otherwise in a credit line to the material. If material is not included in the chapter's Creative Commons license and your intended use is not permitted by statutory regulation or exceeds the permitted use, you will need to obtain permission directly from the copyright holder. 